\title{
Early Linguistic Developments of Simultaneous Bilateral Cochlear Implantees
}

\author{
Michelle J. Suh ${ }^{1}$, Hyun-Jin Lee ${ }^{2}$, and Hyun Seung Choi ${ }^{3}$ \\ ${ }^{1}$ Department of Otorhinolaryngology, Yonsei University College of Medicine, Seoul; and \\ ${ }^{2}$ Department of Otorhinolaryngology, Gyeongsang National University Changwon Hospital, Changwon; and \\ ${ }^{3}$ Department of Otorhinolaryngology, National Health Insurance Service Ilsan Hospital, Goyang, Korea
}

\section{양이 동시 인공와우 사용자의 조기 언어발달}

서지영 ${ }^{1} \cdot$ 이현진 $^{2} \cdot$ 최현승 $^{3}$

연세대학교 의과대학 이비인후과학교실, ${ }^{1}$ 경상대학교 창원병원 이비인후과, ${ }^{2}$ 국민건강보험 일산병원 이비인후과 ${ }^{3}$

Received September 25, 2017
Revised January 21, 2018
Accepted January 23, 2018
Address for correspondence
Hyun Seung Choi, MD
Department of Otorhinolaryngology,
National Health Insurance Service
Ilsan Hospital, 100 Ilsan-ro, Ilsan
dong-gu, Goyang 10444, Korea
Tel +82-31-900-0610
Fax+82-31-900-0613
E-mail choihyunseung@gmail.com
Background and Objectives The present study aimed to compare receptive and expressive language development in children who have undergone simultaneous bilateral cochlear implantation (SCI) and those who have undergone bimodal stimulation (unilateral CI+ hearing aid). Subjects and Method In a retrospective analysis of clinical data, 15 pediatric patients who have received SCI and nine patients who have received bimodal stimulation (BM group) were enrolled. CI was performed for all patients at 24 months of age. Category of Auditory Performance (CAP) scores, Infant-Toddler Meaningful Auditory Integration Scale (IT-MAIS) scores, and developmental quotients (DQ) for expressive and receptive language were compared between the groups at 12 month of follow-up. The Percentage of Consonants Correct (PCC) of children evaluated at 4 years old was also compared.

Results At 12 months of follow-up, significantly greater improvements in CAP scores $(\triangle 4.25 \pm$ $0.5)$ were noted in the SCI group compared to the BM group $(\Delta 3.56 \pm 0.88, p=0.041)$. Significantly greater improvements in IT-MAIS scores were also noted in the SCI group $(\Delta 36.17 \pm$ 4.09) than in the BM group $(\Delta 30.17 \pm 2.91, p=0.004)$. The DQ of receptive language was higher in the SCI group than in the BM group $(87.6 \pm 15.4 \%$ vs. $75.5 \pm 12.0 \%, p=0.023)$ at 12 months of follow-up. Moreover, early SCI was associated with better receptive language skills. PCC index of children at 4 years old was higher in the SCI group than in the BM group (88.5 \pm $13.2 \%$ vs. $62 \pm 15.8 \%, p=0.014)$. Earlier SCI was associated with even greater improvements.

Conclusion Bilateral SCI is associated with significant improvements in language development when compared with bimodal stimulation. Earlier SCI was associated with better outcomes. Korean J Otorhinolaryngol-Head Neck Surg 2018;61(12):650-7

Key Words Category of Auditory Performance · Cochlear implantation · Infant-Toddler Meaningful Auditory Integration Scale • Percentage of consonants correct - Sequenced Language Scale for Infant.

\section{Introduction}

Language delay represents the most common type of de-

This is an Open Access article distributed under the terms of the Creative Commons Attribution Non-Commercial License (https://creativecommons.org/licenses/by-nc/4.0) which permits unrestricted non-commercial use, distribution, and reproduction in any medium, provided the original work is properly cited. velopmental problem, with a prevalence between $7 \%$ and $18 \%$ in 2-year-old children. ${ }^{1)}$ Although there is substantial variability in language development during the early stages of life, ${ }^{2)}$ children with early language delay tend to exhibit difficulties relating to their peers, as well as poor academic performance." Although some children may "catch up" during 
the preschool years, such difficulties often persist into adulthood. Children with severe-to-profound hearing loss exhibit delays in receptive (ability to understand) and expressive (ability to produce) spoken language development. ${ }^{4-7)}$ For these reasons, previous researchers have advocated for early identification of hearing loss and prompt initiation of appropriate interventions. ${ }^{89}$ One such intervention involves early cochlear implantation (CI), thus allowing children access to speech during the critical period, in which brain plasticity is at its peak. ${ }^{10)}$ The general consensus is that implantation should be initiated prior to 3 years of age, as explosive developments in vocabulary and comprehensive ability occur within this window, although some studies have reported greater benefits of CI when performed prior to the age of $2 .^{11,12)}$

Bilateral CI has been supported by recent emphasis on the advantages of bilateral cortical development. ${ }^{13)}$ In addition, electrophysiological studies have revealed that bilateral implants for congenital hearing loss are associated with improvements in hearing rehabilitation due to the development of bilateral auditory pathways without dominance. Furthermore, children who received bilateral implants with an interimplant delay shorter than 12 months exhibit the greatest improvements in speech perception in both quiet and noisy settings. ${ }^{14,15)}$ However, many parents and surgeons opt for bimodal stimulation (BM) (unilateral $\mathrm{CI}+$ hearing aid) due to the burden of bilateral surgery and the proven benefits of BM over unilateral CI for the development of auditory-perceptual skills. ${ }^{16)}$

Although previous researches have focused on language development in children with hearing loss receiving cochlear implant comparing bilateral to unilateral CI, bilateral to bimodal or unilateral to bimodal fittings, no studies to date have compared early linguistic performance in children undergoing "simultaneous" bilateral CI and those receiving BM. ${ }^{16-18)}$ Therefore, in the present study, we focused on relative and absolute language abilities in young children of both groups. Among CI recipients with severe-to-profound prelingual hearing loss, we further analyzed the relationship between linguistic ability and unilateral or bilateral implantation in order to obtain insight into the most appropriate age for CI.

\section{Subjects and Methods}

\section{Selection of patients}

We performed a retrospective review of clinical data from 15 patients (mean age: $13.5 \pm 3.8$ months, age range: $9-22$ months,
$\mathrm{M}: \mathrm{F}=10: 5)$ who had undergone simultaneous $\mathrm{CI}$ and nine (mean age: $17.9 \pm 4.4$ months, age range: $13-24$ months, M:F =2:7) with BM (unilateral CI and hearing aid in opposite ear). Patients with sequential bilateral cochlear CI were excluded. Owing to the retrospective nature of the present study, the requirement for informed consent was waived. CI was performed prior to the age of 24 months at, between 2010 and 2015. Hearing levels were assessed prior to surgery using the auditory brainstem response (ABR) test. Patients were tested via air conduction 1024-click stimuli at a rate of 10 clicks/s at each intensity level under sedation. Auditory steady state responses (ASSR) were elicited by stimuli with carrier frequencies of $0.5,1,2$, and $4 \mathrm{kHz}$. Positive ASSR was considered consistent if positive in at least two frequencies, and ASSR threshold was calculated as the average value obtained for the four frequencies. Category of Auditory Performance (CAP) and Infant-Toddler Meaningful Auditory Integration Scale (IT-MAIS) scores were serially assessed before and after surgery. All patients underwent multichannel CI (bilateral group: five Concerto/Concerto, four CI422/CI422, four CI24RE/CI24RE, one CI422/CI24RE, and one CI512/CI512; bimodal group: six CI24RE, one CI422, one Concerto, and one HiRes90K).

All recipients had used conventional hearing aids for at least 3 months prior to surgery. Patients who had undergone unilateral CI continued to use a hearing aid on the contralateral side postoperatively. All participants were of Korean descent and raised by native Korean speakers, none of whom exhibited any degree of hearing loss. Children with other developmental delays, disabilities other than hearing loss, and inner or middle ear anomalies were excluded. They were followed up for a mean duration of 23.5 months after implantation (range: 12-36 months). All patients were given with speech and auditory rehabilitation by speech and language therapists (twice a week).

\section{Language assessment test}

We evaluated receptive and expressive language development using the Korean Sequenced Language Scale for Infants (SELSI), which is designed to assess both vocabulary and emerging literacy. The SELSI is a comprehensive, standardized tool for the assessment of communication and language in 4- to 36-month-old Korean children and has previously been demonstrated to be valid and reliable in Korean populations. ${ }^{19)}$

The SELSI consists of two sub-tests for receptive and expressive language comprising 56 questions each, for a total of 
112 items. Questions are arranged according to the level of difficulty (14 age-based groups), and language development scores are determined based on development-for-age percentile and age-equivalent scores. Developmental quotients (DQs) for receptive and expressive language were used to objectively compare language delay between the two groups. Each quotient was calculated by dividing developmental age by chronological age (CA) and multiplying by 100 . CAP and ITMAIS scores were also evaluated. ${ }^{20,21)}$ The assessment was conducted by skilled speech therapists via interviews with parents or primary caregivers.

\section{Percentage of consonants correct}

The Percentage of Consonants Correct (PCC) was also used to assess articulation at the age of 4 years. Children were presented with 21 picture cards, which contained a total of 25 words that included 43 Korean consonants. The PCC index was calculated as the number of correct consonants. ${ }^{22)}$ PCC scores are classified into four degrees of severity: mild (more than $85 \%$ correct consonants), mildly moderate (65-85\%), moderately severe (50-65\%), severe (less than 50\%).

\section{Statistical analysis}

PASW Statistics 18 (SPSS Inc., Chicago, IL, USA) was used for all statistical analyses. Continuous variables are expressed as means \pm standard deviation, while categorical variables are expressed as percentages. The level of statistical significance was set at $p<0.05$. Mann-Whitney U-tests were used to evaluate non-normally distributed data for small groups, while regression analyses were used to determine the significance of differences between continuous variables and associations between variables.

\section{Results}

All patients who had undergone simultaneous bilateral CI (SCI group, $n=15)$ exhibited profound hearing loss ( $>90 \mathrm{~dB}$ $\mathrm{HL}$ ), as determined by the ABR test. Among the nine patients of the BM group, thresholds were obtained in four patients, while seven exhibited ASSR responses in at least two frequencies in non-implanted ears. All patients of the BM group used hearing aids in the non-implanted ear (Table 1). Initial CAP scores were lower in the SCI group $(0.86 \pm 0.62)$ than in the BM group (1.44 \pm 1.24$)$, although this difference was not significant ( $\mathrm{U}=47, p=0.238$ ). No significant differences in initial IT-MAIS scores were observed between the SCI group (4.33 \pm 7.57) and BM group (6.44 $\pm 6.88, \mathrm{U}=42.5, p=0.138)$.

\section{CAP and IT-MAIS scores after $\mathbf{C I}$}

Both groups exhibited improvement in auditory performance following CI. Although preoperative CAP scores were not significantly different, the $\triangle \mathrm{CAP} 12$ months after surgery was significantly higher in the SCI group than in the BM group $(\Delta 4.25 \pm 0.5,3.56 \pm 0.88, \mathrm{U}=33.5, p=0.041)$ (Fig. 1).

Although CAP scores at 12 months after CI were not significantly different between the groups $(5.2 \pm 0.4,5.00 \pm 0.7$, $\mathrm{U}=57, p=0.558)$, IT-MAIS scores and improvement values were higher in the SCI group at 12 months after CI com-

Table 1. Demographic characteristics of each patient group

\begin{tabular}{|c|c|c|c|}
\hline & Simultaneous bilateral $\mathrm{Cl}(\mathrm{n}=15)$ & \multicolumn{2}{|c|}{ Bimodal $\mathrm{Cl}(\mathrm{n}=9)$} \\
\hline Age at operation (months) & $13.5 \pm 3.8$ (range 9-22) & \multicolumn{2}{|c|}{$17.9 \pm 4.4$ (range $13-24)$} \\
\hline Duration of hearing with $\mathrm{Cl}$ & $25.8 \pm 10.9$ & \multicolumn{2}{|c|}{$19.7 \pm 7.6$} \\
\hline \multicolumn{4}{|l|}{$\operatorname{Sex}(\%)$} \\
\hline Male & $10(66.7)$ & \multicolumn{2}{|c|}{$2(22.2)$} \\
\hline Female & $5(33.3)$ & \multicolumn{2}{|c|}{$7(77.8)$} \\
\hline \multirow[t]{2}{*}{ ABR threshold } & Implanted ears & Implanted ear & Contralateral ear \\
\hline & $(n=15,30$ ears $)$ & $(n=9$, ears $)$ & $(n=9$, ears $)$ \\
\hline $70-90 \mathrm{~dB} n \mathrm{nH}(\%)$ & - & $1(11.1)$ & $3(33.3)$ \\
\hline$>90 \mathrm{~dB} \mathrm{nHL}(\%)$ & $4(13.3)$ & $1(11.1)$ & $1(11.1)$ \\
\hline No response (\%) & $26(86.7)$ & $7(77.8)$ & $5(55.6)$ \\
\hline ASSR threshold & Implanted ears & Implanted ear & Contralateral ear \\
\hline 70-90 dB nHL (\%) & - & - & $1(11.1)$ \\
\hline$>90 \mathrm{~dB} \mathrm{nHL}(\%)$ & $13(43.3)$ & $6(66.7)$ & $6(66.7)$ \\
\hline No response (\%) & $17(56.7)$ & 3 (33.3) & $2(22.2)$ \\
\hline
\end{tabular}

Group A (simultaneous bilateral $\mathrm{Cl}, \mathrm{n}=15$ ), Group B (bimodal $\mathrm{Cl}, \mathrm{n}=9$ ), ASSR threshold=average of $0.5,1,2$, and $4 \mathrm{kHz}$, values are mean \pm standard deviation. Cl: cochlear implantation, ABR: auditory brainstem responses, ASSR: auditory steady state responses 
pared with those in the BM group (IT-MAIS score: $40.00 \pm 0$, $36 \pm 4.40, \mathrm{U}=15, p=0.01$ ) ( $\Delta$ IT-MAIS score $=36.17 \pm 4.09,30.17 \pm$ 2.91, $\mathrm{U}=18.5, p=0.004$ ) (Fig. 2). These results indicated that the SCI group exhibited greater improvement in general auditory performance during the first year after CI.

\section{Comparison of receptive and expressive language scores}

The DQ, which was defined as the ratio of age equivalent to CA, was compared between the two groups to evaluate receptive and expressive language development prior to and following implantation (Fig. 3). No significant differences in either receptive or expressive language were observed between the SCI group and BM group (receptive: $41.27 \pm 27.68$ and $34.3 \pm 11.1, \mathrm{U}=65, p=0.88$, respectively) (expressive: $44.06 \pm$ 19.12 and $35.9 \pm 9.11, \mathrm{U}=64.5, p=0.861$ ) (Fig. $3 \mathrm{~A}$ and $\mathrm{C}$ ) prior to implantation. However, 12 months following implantation, the average DQ of receptive language in the SCI group $(87.6 \pm 15.4 \%)$ was significantly higher than that of the BM group (75.5 $\pm 12.0 \%, \mathrm{U}=10, p=0.023)$ (Fig. 3B). The postoperative DQ of expressive language was also higher in the SCI group $(81.6 \pm 20.8)$ than in the BM group (57.5 \pm 37.5$)$, although this difference was not significant $(\mathrm{U}=16, p=0.098)$ (Fig. 3D).

Earlier implantation resulted in better receptive language performance at 12 months post-op but not expressive language performance in the SCI group ( $p=0.017, p=0.326$, respective-
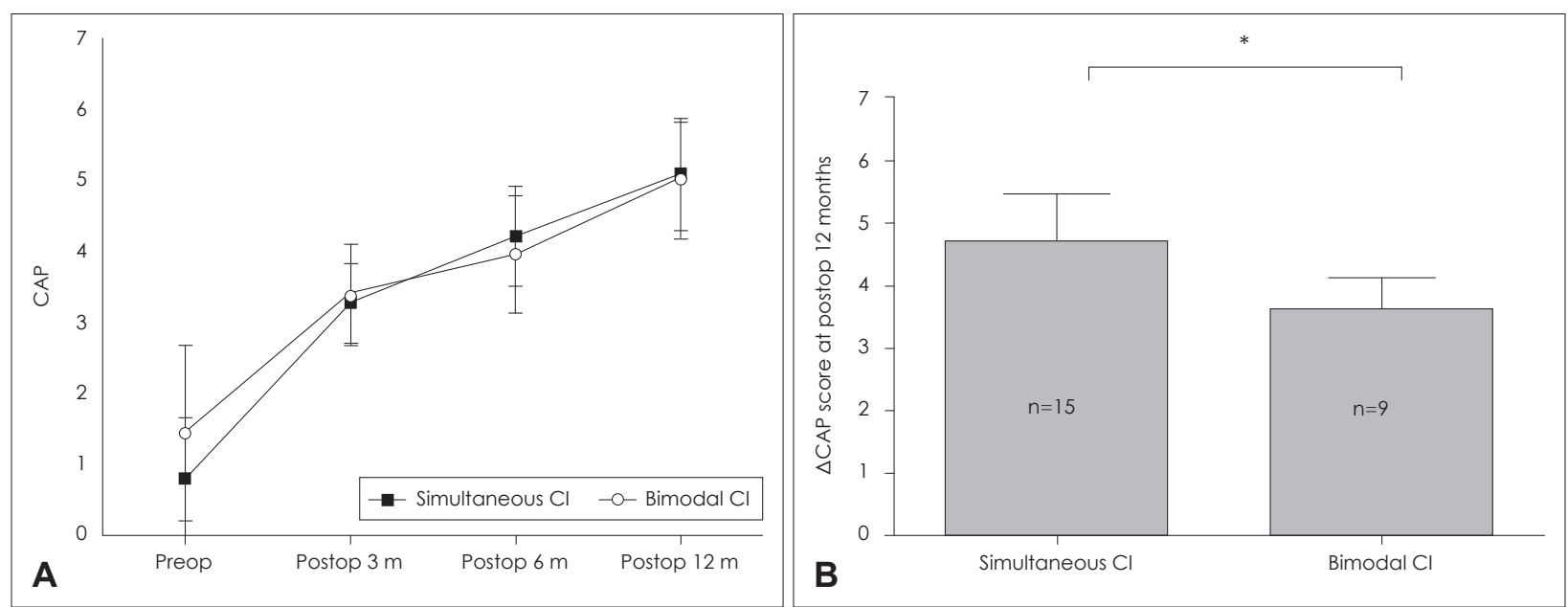

Fig. 1. Comparison of pre-operative and post-operative CAP scores in the simultaneous bilateral and bimodal groups (A). Serial changes in CAP after cochlear implantation (B) $\triangle$ CAP score at postoperative 12 months. Bars indicate means \pm standard deviation. $*$ statistical significance $(p<0.05)$, simultaneous group: $n=15$, unilateral group: $n=9$. Cl: cochlear implantation, CAP: Category of Auditory Performance.
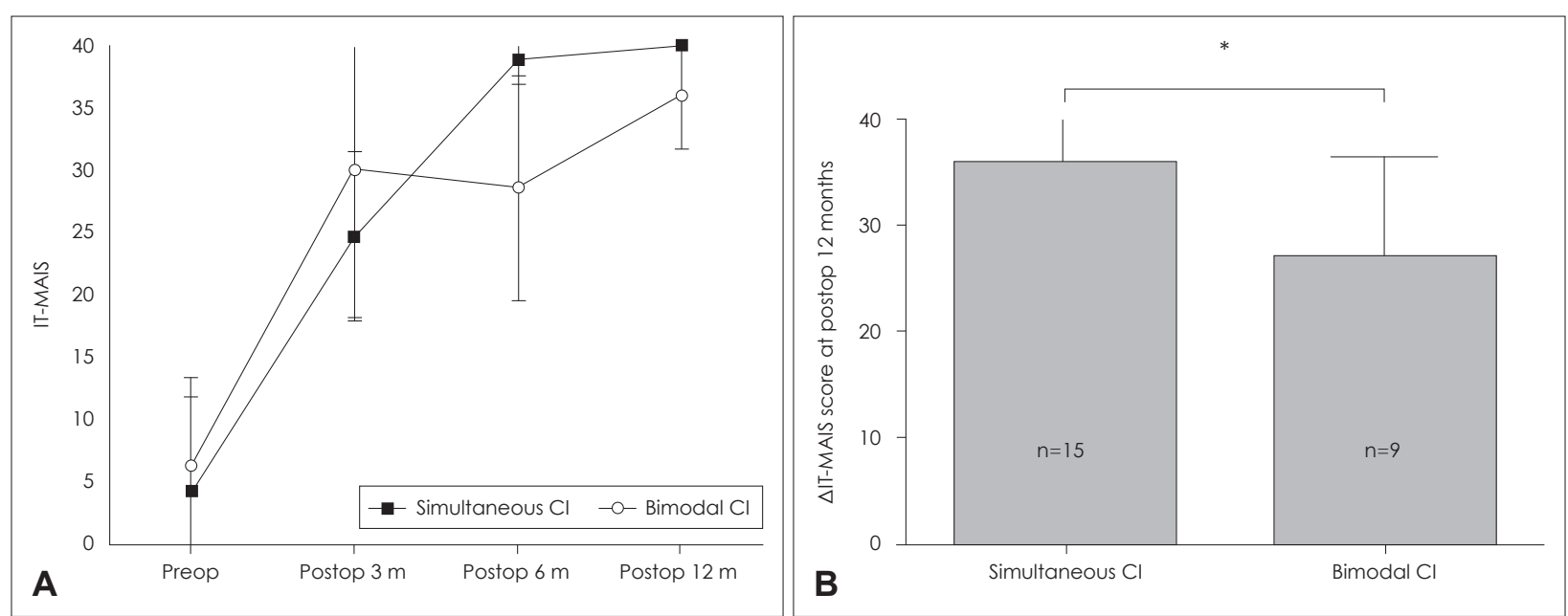

Fig. 2. Comparison of pre-operative and post-operative IT-MAIS scores in the simultaneous bilateral and bimodal groups (A). Serial changes in IT-MAIS after cochlear implantation (B) $\triangle I T-M A I S$ score at postoperative 12 months. Bars indicate means \pm standard deviation. *statistical significance $(p<0.01)$, simultaneous group: $n=15$, bimodal group: $n=9$. Cl: cochlear implantation, IT-MAIS: Infant-Toddler Meaningful Auditory Integration Scale. 

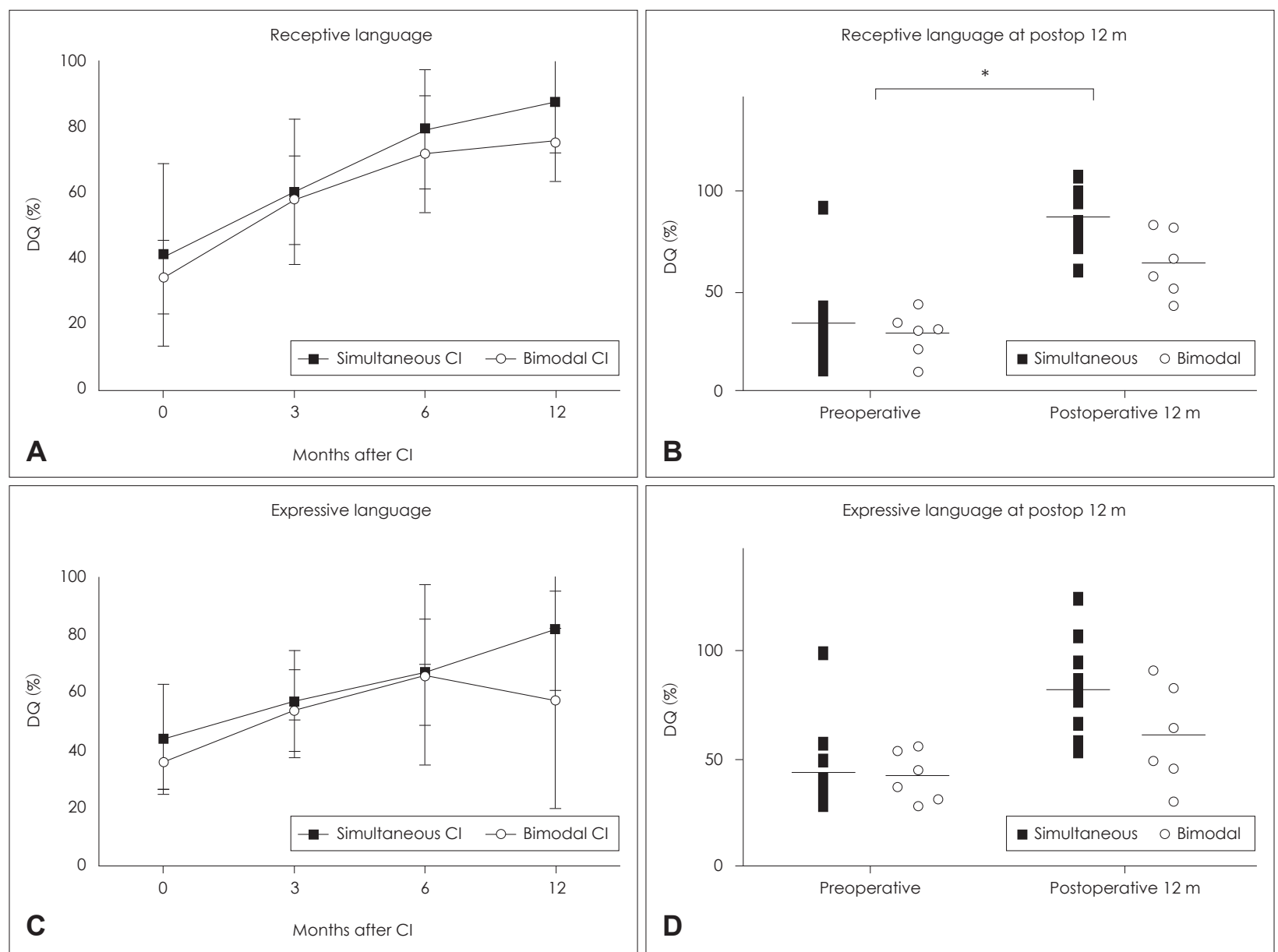

Fig. 3. Changes in receptive $(A)$ and expressive $(C) D Q$ in the simultaneous $\mathrm{Cl}$ and bimodal $\mathrm{Cl}$ group. $\mathrm{DQ}$ at postoperative 12 months in receptive (B) and expressive (D) language in the $\mathrm{SCl}$ and $\mathrm{BM}$ groups. Bars indicate means \pm standard deviation. *statistical significance $(p<0.05)$, simultaneous group: $n=11$, unilateral group: $n=6$. DQ: developmental quotient, Cl: cochlear implantation, SCl: simultaneous bilateral cochlear implantation, BM: bimodal stimulation.

ly) (Fig. 4). However, we observed no correlation between the timing of operation and either linguistic category in the BM group (receptive: $p=0.523$, expressive: $p=0.523$ ) (Fig. 4B).

\section{Comparison of PCC scores at age 4}

We evaluated pronunciation accuracy in both groups using the PCC index when patients had reached age 4 (Fig. 5). The SCI group exhibited significantly higher PCC scores (88.5 \pm $13.2 \%)$ than the BM group $(62 \pm 15.8 \%, \mathrm{U}=4.5, p=0.014)$ without differences in duration of $\mathrm{CI}$ use. According to the proposed classification, ${ }^{20)}$ PCC scores over $85 \%$ indicate mild impairments in pronunciation, while scores between $50 \%$ and $65 \%$ indicate moderate-to-severe impairments. Moreover, early implantation was associated with higher PCC values in all patients and in those of the SCI group ( $p<0.001$ in all patients, $p=0.036$ in SCI group) (Fig. 5B).

\section{Discussion}

Bilateral CI enables binaural hearing in prelingual deaf children, resulting in better language development than unilateral $\mathrm{CI}^{23,24)}$ In patients for whom bilateral $\mathrm{CI}$ is necessary, $\mathrm{SCI}$ is recommended rather than sequential $\mathrm{CI}$, which can result in aural preference syndrome. Furthermore, simultaneous implantation reduces hospital stay and cumulative anesthetic time. ${ }^{25,26)}$ However, the comparative efficacy of BM and bilateral CI remains somewhat controversial. Some researchers have also argued that natural sound experience through bimodal hearing is superior to bilateral electrical stimulation in noisy conditions and in the perception of music. $^{27,28)}$

Furthermore, previous research has demonstrated the benefits of BM during early childhood, as the addition of a lowfrequency acoustic signal enhances language acquisition 


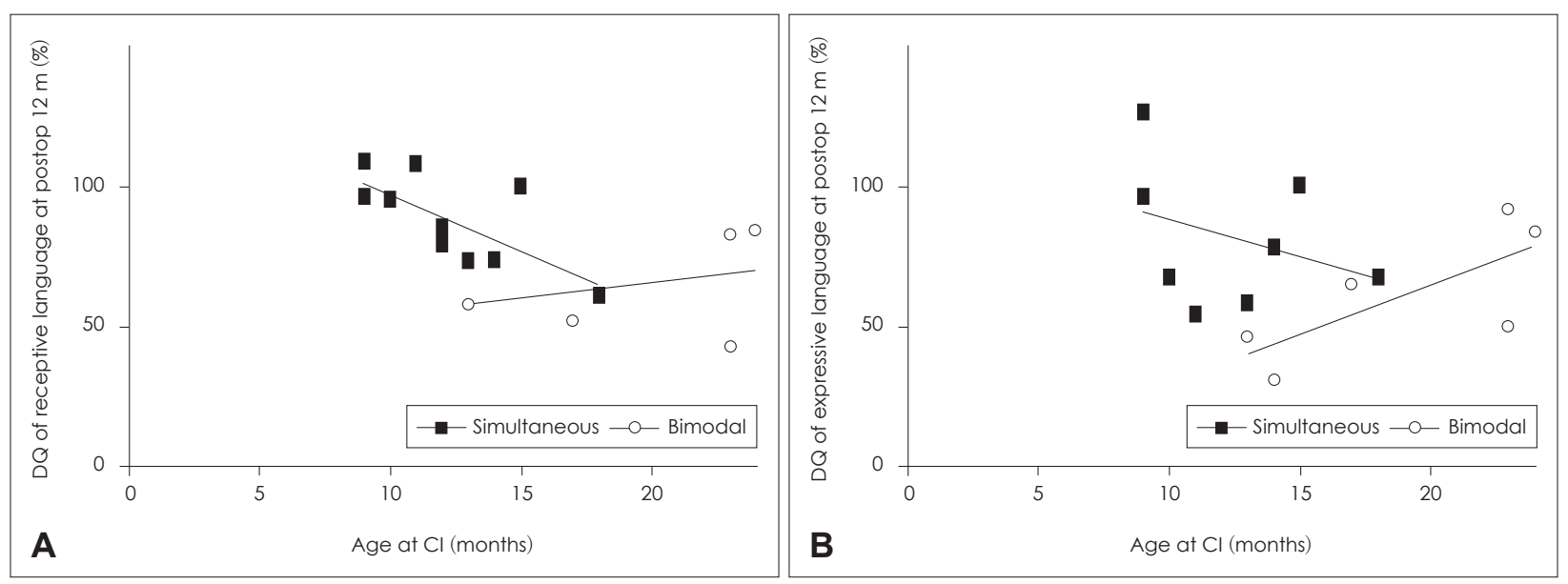

Fig. 4. Relationships between age at $\mathrm{Cl}$ and $\mathrm{DQ}$ for receptive language $\left(\mathrm{SCl}: \mathrm{r}^{2}=0.489, p=0.017, \mathrm{BCl}: \mathrm{r}^{2}=0.109, p=0.523\right)(\mathrm{A})$ and expressive language $\left(\mathrm{SCl}: \mathrm{r}^{2}=0.107, p=0.326, \mathrm{BCl}: \mathrm{r}^{2}=0.537, p=0.097\right)(\mathrm{B})$. Simple regression analysis showed a significant negative correlation between age at $\mathrm{Cl}$ and receptive language capabilities. $\mathrm{Cl}$ : cochlear implantation, $\mathrm{DQ}$ : developmental quotient, $\mathrm{SCl}$ : simultaneous bilateral cochlear implantation, $\mathrm{BCl}$ : bimodal cochlear implantation.
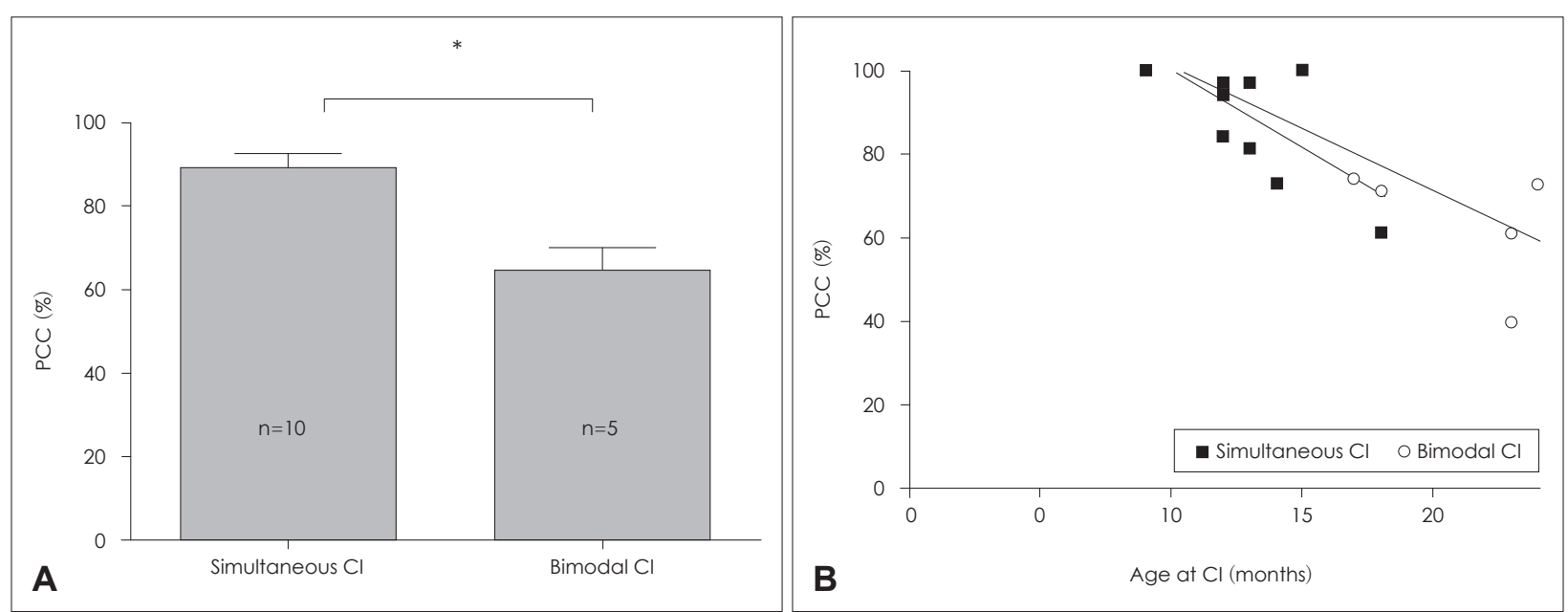

Fig. 5. Comparison of $\mathrm{PCC}$ at the chronological age of 4 years in the $\mathrm{SCl}$ and $\mathrm{BCl}$ groups $(\mathrm{A})$. Linear regression in all patients and those of the SCl group showed a significant negative correlation between age at $\mathrm{Cl}$ and PCC (\%) (overall group: $\mathrm{r}^{2}=0.647, p<0.001, \mathrm{SCl}$ group: $\left.r^{2}=0.443, p=0.036\right)(B)$. Bars indicate means \pm standard deviation. $*$ statistical significance $(p<0.05)$. PCC: Percentage of Consonants Correct, $\mathrm{r}^{2}$ : correlation coefficient, $\mathrm{Cl}$ : cochlear implantation, $\mathrm{SCl}$ : simultaneous bilateral cochlear implantation, $\mathrm{BCl}$ : bimodal cochlear implantation.

during this critical period. However, such studies have primarily focused on the advantages of BM over single-CI only. Moreover, such studies have acknowledged that BM alone cannot fully overcome impairments in the use of binaural cues and abnormal auditory cortical development due to delayed sequential CI. In addition, the authors of these studies have highlighted the advantages of bilateral CI with regard to sound localization and hearing in noisy environments. ${ }^{29,30)}$

Our findings indicated that children who had received SCI developed language skills (as measured using the CAP and ITMAIS) at a faster pace than those of the BM group, with significantly greater improvements at the 12-month follow-up. These results may indicate that the residual hearing of chil- dren in the present study was inappropriate for BM. In the BM group, the average residual hearing of the non-implanted ear was $90 \mathrm{~dB}$ or greater (based on ASSR) in all but one patient. However, considering the diverse frequencies of residual hearing for each patient, a simple mean value may not be sufficient for determining whether a bimodal benefit is present. Previous studies have reported that residual hearing in the non-implanted ear was mostly $90 \mathrm{~dB}$ HL or greater, noting binaural improvements in approximately $62 \%$ of patients. ${ }^{31,32)}$ Listeners with severe or profound impairments at $500 \mathrm{~Hz}$ were capable of extracting some speech information from audible signals in the non-implanted ear when combined with electrical stimulation in the implanted ear, al- 
though a sufficient level of stimulation cannot be guaranteed in all cases. ${ }^{32)}$ These findings therefore suggest that $\mathrm{SCI}$ is more advantageous for language development than $\mathrm{BM}$ when residual hearing falls below $90 \mathrm{~dB} \mathrm{HL}$.

Both the CAP and IT-MAIS are advantageous in that they are simple and effective methods of assessment; however, due to their ceiling effects, the SELSI test was required for a more accurate assessment. Our findings revealed that receptive and expressive language development was significantly improved in the SCI group 12 months following implantation. Moreover, patients of the SCI group exhibited superior performance in pronunciation when compared to those of the BM group at the age of 4 years, suggesting that SCI offers distinct advantages in promoting accurate pronunciation and early language capabilities. In the present study, we restricted our analyses to toddlers and children of preschool age, a critical period for linguistic development. Appropriate auditory phonological input during this period ensures central auditory development at an early age. Furthermore, Fenson, et al. ${ }^{33}$ suggested that, for spoken language, the early linguistic gap gets wider as children grow without proper input.

Interestingly, early linguistic development was correlated with age at CI among patients of the SCI group who had undergone CI within the first 24 months of life, although this correlation was not observed for patients in the BM group. Age at implantation is a well-known prognostic factor even in unilateral CI. Leigh, et al. ${ }^{34)}$ reported that children implanted between 6 and 12 months of age exhibited much faster rates of language growth compared with children implanted between 13 and 24 months of age, whose performance did not match that of their peers until 3 years after implantation. Taken together, these findings suggest that simultaneous implantation is more successful when performed prior to the age of 12 months. Furthermore, a recent study reported that CI prior to the age of 12 months facilitates speech production accuracy in children with severe-to-profound bilateral hearing loss. ${ }^{35)}$ In accordance with these findings, our results indicated that earlier simultaneous implantation resulted in greater improvements in speech accuracy and comprehension (Figs. 4 and 5).

In the present study, early implantation (within 24 months) was closely correlated with language development in the SCI group. Although such early implantation has been associated with improved linguistic performance, residual hearing levels are important to consider when evaluating the potential benefits of early SCI. Residual hearing must be accurately measured in the infant, as ASSR and ABR are highly correlated with later pure-tone audiometry measurements in children with severe-to-profound hearing loss. ${ }^{36-38)}$ However, there may be dyssynchrony in these measurements in patients with auditory neuropathy. ${ }^{39)}$

\section{Limitations}

The present study possesses some limitations of note. Because of the small number of patients included in the retrospective analysis, matching based on age at implantation was difficult. However, we accounted for the influence of earlier surgery within each group analysis. Our results indicated that earlier implantation was associated with better outcomes in the SCI group. However, this tendency was not observed in the BM group, indicating that these benefits are not determined solely based on the age at implantation. Furthermore, there was no significant difference in CAP, IT-MAIS, or SELSI scores between the two groups prior to surgery. This ensured that, despite the differences in age at implantation, baseline performance was similar. Furthermore, although bilateral hearing loss was defined as profound based on ABR results, these results differed somewhat from those of the ASSR. In addition, despite health insurance coverage of bilateral $\mathrm{CI}$ for the treatment of profound hearing loss is based on $\mathrm{ABR}$ results before the age of 2 years, the socioeconomic status should also be considered in future studies of bilateral implantation. Last, although the focus of this study is on early language development with SCI or BM conditions, longterm follow-up observation how this result correlates with the language skills of school age should be examined.

In conclusion, In the present study, bilateral simultaneous cochlear implantation prior to the age of 24 months resulted in significantly greater linguistic ability in the preschool years when compared with BM. Earlier intervention within the SCI group resulted in even greater improvements. Therefore, if accurate hearing measurements are available, early SCI should be considered a priority for children with profound bilateral hearing loss. The present data demonstrate that early binaural input is necessary for appropriate language development during critical periods, and that parents should be informed of the benefits of bilateral simultaneous implantation prior to surgery.

\section{Acknowledgments}

The authors wish to thank all patients for their participation in the study. 


\section{REFERENCES}

1) Rescorla $L$. The language development surveya screening tool for delayed language in toddlers. J Speech Hear Disord 1989;54(4):58799.

2) Bates E, Dale PS, Thal D. Individual differences and their implications for theories of language development. In: Fletcher P, MacWhinney B, editors. The Handbook of Child Language. Oxford: Blackwell; 1995. p.96-151.

3) Toppelberg CO, Shapiro T. Language disorders: a 10-year research update review. J Am Acad Child Adolesc Psychiatry 2000;39(2):14352 .

4) Geers AE, Moog JS. Factors predictive of the development of literacy in profoundly hearing-impaired adolescents. Volta Rev 1989;91:69-86.

5) Moeller MP, Osberger MJ, Eccarius M. Language and learning skills of hearing-impaired students. receptive language skills. ASHA Monogr 1986;(23):41-53.

6) Levitt H, McGarr N, Geffner D. Development of language and communication skills in hearing-impaired children. introduction. ASHA Monogr 1987;(26):1-8.

7) Quigley SP. Environment and communication in the language development of deaf children. In: Bradford LJ, Hardy WG, editors. Hearing and Hearing Impairment. New York, NY: Grune and Stratton;1979. p.287-98.

8) Kennedy CR, McCann DC, Campbell MJ, Law CM, Mullee M, Petrou S, et al. Language ability after early detection of permanent childhood hearing impairment. N Engl J Med 2006;354(20):2131-41.

9) Ptok M. Early detection of hearing impairment in newborns and infants. Dtsch Arztebl Int 2011;108(25):426-31.

10) Waltzman SB, Roland JT Jr. CI in children younger than 12 months. Pediatrics 2005;116(4):e487-93.

11) Svirsky MA, Teoh SW, Neuburger H. Development of language and speech perception in congenitally, profoundly deaf children as a function of age at CI. Audiol Neurootol 2004;9(4):224-33.

12) Cheng AK, Grant GD, Niparko JK. Meta-analysis of pediatric cochlear implant literature. Ann Otol Rhinol Laryngol Suppl 1999; 177:124-8.

13) Bauer PW, Sharma A, Martin K, Dorman M. Central auditory development in children with bilateral cochlear implants. Arch Otolaryngol Head Neck Surg 2006;132(10):1133-6.

14) Gordon KA, Valero J, Papsin BC. Binaural processing in children using bilateral cochlear implants. Neuroreport 2007;18(6):613-7.

15) Salloum CA, Valero J, Wong DD, Papsin BC, van Hoesel R, Gordon KA. Lateralization of interimplant timing and level differences in children who use bilateral cochlear implants. Ear Hear 2010;31(4): 441-56.

16) Marsella P, Giannantonio S, Scorpecci A, Pianesi F, Micardi M, Resca A. Role of bimodal stimulation for auditory-perceptual skills development in children with a unilateral cochlear implant. Acta Otorhinolaryngol Ital 2015;35(6):442-8.

17) Sarant J, Harris D, Bennet L, Bant S. Bilateral versus unilateral cochlear implants in children: a study of spoken language outcomes. Ear Hear 2014;35(4):396-409.

18) Ching TY, Day J, Van Buynder P, Hou S, Zhang V, Seeto M, et al. Language and speech perception of young children with bimodal fitting or bilateral cochlear implants. Cochlear Implants Int 2014;15 Suppl 1:S43-6.

19) Kim YT. Content and reliability analyses of the Sequenced Language Scale for Infants (SELSI). Commun Sci Disord 2002;7(2):1-23.
20) Archbold S, Lutman ME, Marshall DH. Categories of auditory performance. Ann Otol Rhinol Laryngol Suppl 1995;166:312-4.

21) Zimmerman-Phillips S, Robbins AM, Osberger MJ. Assessing cochlear implant benefit in very young children. Ann Otol Rhinol Laryngol Suppl 2000;185:42-3.

22) Shriberg LD, Kwiatkowski J. Phonological disorders I: a diagnostic classification system. J Speech Hear Disord 1982;47(3):226-41.

23) Wie OB. Language development in children after receiving bilateral cochlear implants between 5 and 18 months. Int J Pediatr Otorhinolaryngol 2010;74(11):1258-66.

24) Brown KD, Balkany TJ. Benefits of bilateral CI: a review. Curr Opin Otolaryngol Head Neck Surg 2007;15(5):315-8.

25) Gordon KA, Wong DD, Papsin BC. Cortical function in children receiving bilateral cochlear implants simultaneously or after a period of interimplant delay. Otol Neurotol 2010;31(8):1293-9.

26) Gordon KA, Wong DD, Papsin BC. Bilateral input protects the cortex from unilaterally-driven reorganization in children who are deaf. Brain 2013;136(Pt 5):1609-25.

27) Offeciers E, Morera C, Müller J, Huarte A, Shallop J, Cavallé L. International consensus on bilateral cochlear implants and bimodal stimulation. Acta Otolaryngol 2005;125(9):918-9.

28) Sucher CM, McDermott HJ. Bimodal stimulation: benefits for music perception and sound quality. Cochlear Implants Int 2009;10 Suppl 1:96-9.

29) Nittrouer $S$, Chapman $C$. The effects of bilateral electric and bimodal electric--acoustic stimulation on language development. Trends Amplif 2009;13(3):190-205.

30) Moberly AC, Lowenstein JH, Nittrouer S. Early bimodal stimulation benefits language acquisition for children with cochlear implants. Otol Neurotol 2016;37(1):24-30.

31) Ching TY, van Wanrooy E, Dillon H. Binaural-bimodal fitting or bilateral implantation for managing severe to profound deafness: a review. Trends Amplif 2007;11(3):161-92.

32) Ching TY. The evidence calls for making binaural-bimodal fittings routine. Hear J 2005;58(11):32-4.

33) Fenson L, Dale PS, Reznick JS, Bates E, Thal DJ, Pethick SJ. Variability in early communicative development. Monogr Soc Res Child Dev 1994;59(5):1-173; discussion 174-85.

34) Leigh J, Dettman S, Dowell R, Briggs R. Communication development in children who receive a cochlear implant by 12 months of age. Otol Neurotol 2013;34(3):443-50.

35) Dettman SJ, Dowell RC, Choo D, Arnott W, Abrahams Y, Davis A, et al. Long-term communication outcomes for children receiving cochlear implants younger than 12 months: a multicenter study. Otol Neurotol 2016;37(2):e82-95.

36) Dimitrijevic A, John MS, Van Roon P, Purcell DW, Adamonis J, Ostroff J, et al. Estimating the audiogram using multiple auditory steady-state responses. J Am Acad Audiol 2002;13(4):205-24.

37) Ahn JH, Lee HS, Kim YJ, Yoon TH, Chung JW. Comparing pure-tone audiometry and auditory steady state response for the measurement of hearing loss. Otolaryngol Head Neck Surg 2007;136(6):966-71.

38) van der Drift JF, Brocaar MP, van Zanten GA. The relation between the pure-tone audiogram and the click auditory brainstem response threshold in cochlear hearing loss. Audiology 1987;26(1):1-10.

39) Berlin CI, Hood L, Morlet T, Rose K, Brashears S. Auditory neuropathy/ dys-synchrony: diagnosis and management. Ment Retard Dev Disabil Res Rev 2003;9(4):225-31. 